\begin{tabular}{|c|l|}
\hline Title & Effective species for ignition of premixed burner flame in effluent of dielectric barrier discharge \\
\hline Author(s) & Sasaki, Koichi; Deguchi, Y usei \\
\hline Citation & $\begin{array}{l}\text { Japanese Journal of A pplied Physics (JJA P), 57(9), 096102 } \\
\text { https://doi.org/L0.7567/JJA.57.096102 }\end{array}$ \\
\hline Issue Date & 2018-09 \\
\hline Doc URL & http://hdl.handle.net/2115/75312 \\
\hline Rights & ○ 2018The Japan Society of A pplied Physics \\
\hline Type & article (author version) \\
\hline File Information & RP180222.pdf \\
\hline
\end{tabular}

Instructions for use 


\title{
Effective species for ignition of premixed burner flame in effluent of dielectric barrier discharge
}

\author{
Koichi Sasaki* and Yusei Deguchi
}

Division of Quantum Science and Engineering, Hokkaido University, Sapporo 060-8628, Japan

\begin{abstract}
The ignition probability of a premixed burner flame was improved in the effluent of a dielectric barrier discharge. In addition, the propagation speed of the flame kernel was increased by the dielectric barrier discharge. The increase in the propagation speed of the flame kernel was more significant in the region close to the nozzle of the effluent gas. We measured the spatial distributions of the densities of $\mathrm{OH}$ and atomic oxygen in the effluent. We found that the axial decay of the density of atomic oxygen was steeper than that of the $\mathrm{OH}$ density under the experimental conditions. By comparing the spatial distributions of the radical densities with that of the propagation speed of the flame kernel, we concluded that atomic oxygen works more effectively than $\mathrm{OH}$ in improving the ignition probability of the premixed burner flame.
\end{abstract}

\section{Introduction}

This work is related to the investigation of the mechanism of plasma-assisted combustion. Plasma-assisted combustion attracts much attention as an interdisciplinary field between plasma science and combustion engineering. ${ }^{1-5)}$ It has potential in reducing the consumption of fossil fuels by realizing combustion under lean-fuel conditions. In addition, it is effective for combustion in high-speed flow, ${ }^{6-10)}$ for stabilizing a flame, ${ }^{11-13)}$ for increasing the burning velocity, ${ }^{14-18)}$ for improving ignition characteristics, ${ }^{19-25)}$ and for the use of alternative fuels. However, the mechanism of the improved combustion and ignition characteristics has not been fully understood yet. The thermal effect, or the effect of the heated gas temperature in the plasma, is understood rather easily on the basis of chemistry in thermodynamic equilibrium. In contrast, it is difficult to obtain detailed understanding of kinetic effects in nonequilibrium plasmas. The electron temperature in a nonequilibrium plasma is higher than the gas temperature, and various reactive species, such as neutral radicals, ions, electronic excited states, and vibrational excited states, are produced by electron impact processes. A fundamental issue is the identification of the key reactive species, which enhances the combustion chemistry. Atomic oxygen is considered to be an important reactive species in many

*E-mail: sasaki@qe.eng.hokudai.ac.jp 
papers, ${ }^{4,5,26-28)}$ whereas some papers point out the importance of $\mathrm{OH}^{29,30)}$

In our previous works, we have examined the effect of the dielectric barrier discharge (DBD) on the burning velocity in a steady-state premixed burner flame. ${ }^{31-34)}$ The experimental results indicate that atomic oxygen produced in the preheating zone is the origin of the activated combustion reactions. This conclusion was obtained by a high-resolution experiment in the transition part between the unburned gas and the reaction zone in the steady-state flame. ${ }^{33)}$ In the present work, we observed the propagation speed of the flame kernel in the effluent of DBD. The reason why we employed this experimental method in the present work is that the radial structure of the steady-state premixed burner flame from the unburned gas to the reaction zone via the preheating zone has an analogy with the temporal evolution of the flame ignition. The preheating zone in the spatial structure of the steady-state flame corresponds to the period between the initiation of chemical reactions and the abrupt increase in gas temperature. Measurements with a fine spatial resolution less than $0.1 \mathrm{~mm}$ are necessary to observe the processes in the preheating zone, whereas temporally resolved measurements in the period between the initiation of chemical reactions and the abrupt increase in gas temperature are much easier. In this paper, we report the comparison between the propagation speed of the flame kernel and the densities of $\mathrm{OH}$ and atomic oxygen in the effluent of DBD. We identified the effective species for increasing the propagation speed of the flame kernel.

\section{Experimental methods}

The experimental apparatus used is schematically shown in Fig. 1. We constructed a laboratory-made gas burner for this experiment. The bottom half of the burner was a stainlesssteel vessel that was electrically grounded. A tungsten rod with a diameter of $0.5 \mathrm{~mm}$ was attached at the center of the stainless-steel vessel. The upper half of the burner was made of quartz. The inner and outer diameters of the quartz tube were 7 and $10 \mathrm{~mm}$, respectively. The premixed gas of $\mathrm{Ar}, \mathrm{O}_{2}$, and $\mathrm{CH}_{4}$ was introduced from the stainless-steel vessel toward the top of the quartz tube. We used Ar instead of $\mathrm{N}_{2}$ in a series of our works ${ }^{31-34)}$ to avoid the optical emission of the $\mathrm{N}_{2}$ second positive system, which contaminated the optical emission spectrum of the $\mathrm{OH} \mathrm{A}{ }^{2} \Sigma^{+}-\mathrm{X}^{2} \Pi$ transition. The flow rates of $\mathrm{Ar}, \mathrm{O}_{2}$, and $\mathrm{CH}_{4}$ were controlled using mass flow controllers and adjusted at 2.25, 0.4, and $0.2 \mathrm{slm}$, respectively. The stoichiometric mixture was chosen for the flow rates of $\mathrm{O}_{2}$ and $\mathrm{CH}_{4}$ to carry out a simple experiment. The flow rate of Ar was adjusted immediately below the value that resulted in the blow-off of the steady-state burner flame. The flow velocity, which had a radial distribution, was evaluated by solving the Navier-Stokes equation to be approximately $2 \mathrm{~m} / \mathrm{s}$ at its maximum at the 
above flow rates. The gas residence time corresponding to a flow velocity of $2 \mathrm{~m} / \mathrm{s}$ was $7 \mathrm{~ms}$ in the observation region. A laminar flow was observed in the region within a distance of 60 $\mathrm{mm}$ from the top of the quartz tube at the above flow rates. The production of DBD caused a perturbed flow at the upper part, but the laminar flow was maintained in the observation region near the top of the quartz tube $(\leq 15 \mathrm{~mm})$. The premixed gas passed through distilled water in some experiments to add water vapor.

An aluminum ring electrode was attached to the outside of the quartz tube and connected to a high-voltage power supply. The power supply provided a rectangular (or trapezoidal) waveform with a rise time constant of $0.13 \mathrm{kV} / \mu$ s at a frequency of $4 \mathrm{kHz}$. The frequency of the power supply was chosen to be much higher than the reciprocal of the lifetimes of radicals to realize their constant densities. An asymmetric dielectric barrier discharge (DBD) was thus produced inside the quartz tube between the ring electrode and the tungsten rod. The discharge powers, which were measured using the V-Q Lissajous method, were 0.5 and 0.4 $\mathrm{W}$ in the cases without and with the addition of water vapor, respectively. The laser-induced ignition experiment was carried out in the effluent of DBD. The second harmonics of the $\mathrm{Nd}$ :YAG laser at a wavelength of $532 \mathrm{~nm}$ was focused onto the effluent of DBD using a lens with a focal length of $150 \mathrm{~mm}$. The distance between the top of the quartz tube and the focal point of the Nd:YAG laser beam was $4 \mathrm{~mm}$. The top of the quartz tube worked as the nozzle of the burner, and a premixed burner flame with a conical shape was formed above the quartz tube when the energy of the Nd:YAG laser was sufficiently high.

We examined the propagation of the flame kernel using a shadowgraph imaging method. The region around the focal point of the Nd:YAG laser beam was illuminated using a Xe lamp, and the pattern of the transmitted lamp light was captured using a high-speed camera. We obtained a high-speed movie that represented the shape and propagation speed of the flame kernel in the effluent of DBD. We also measured the radial distribution of the gas temperature by laser Rayleigh scattering. A laser beam at a wavelength of $250 \mathrm{~nm}$, which was produced using an optical parametric oscillator (OPO), was injected into the effluent from the radial direction. The laser beam was focused using a lens with a focal length of 250 $\mathrm{mm}$, and the distance between the laser beam and the top of the quartz tube was $3 \mathrm{~mm}$. The intensity of the scattered laser light was captured using a charge-coupled device camera with a gated image intensifier (ICCD camera) from the right angle to the incident laser beam. The gas temperature $T$ was evaluated using $T=T_{0}\left(I_{0} / I\right)$, where $I$ and $I_{0}$ are the scattered light intensities with and without DBD, respectively, and $T_{0}$ is the gas temperature in the absence of DBD. 
To identify the most effective reactive species for the ignition of the premixed burner flame, we measured the densities of $\mathrm{OH}$ radicals and atomic oxygen in the effluent by laserinduced fluorescence (LIF) spectroscopy. In the measurement of the $\mathrm{OH}$ density, the OPO laser beam was tuned at a wavelength of $261.68 \mathrm{~nm}$, by which $\mathrm{OH}$ radicals in the ground state $\left[X^{2} \Pi\left(v^{\prime \prime}=0\right)\right]$ were excited to the $A^{2} \Sigma\left(v^{\prime}=2\right)$ state. We employed this $v^{\prime \prime}=0 \rightarrow v^{\prime}=2$ excitation scheme to obtain a higher signal-to-noise ratio. The laser beam was injected into the effluent in the same manner as that in the Rayleigh scattering experiment. The laser beam had a uniform intensity in the effluent region because of the long focal length of the focusing lens. The uniformity of the laser beam was confirmed from the distribution of the intensity of Rayleigh scattering along the path of the laser beam in the absence of DBD. The laser-induced fluorescences produced by spontaneous transitions from $A^{2} \Sigma\left(v^{\prime}=2\right)$ to $X^{2} \Pi\left(v^{\prime \prime}=2\right)$, from $A^{2} \Sigma\left(v^{\prime}=1\right)$ to $X^{2} \Pi\left(v^{\prime \prime}=1\right)$, and from $A^{2} \Sigma\left(v^{\prime}=0\right)$ to $X^{2} \Pi\left(v^{\prime \prime}=0\right)$ were captured using the ICCD camera. The transitions from $A^{2} \Sigma\left(v^{\prime}=2\right)$ to $A^{2} \Sigma\left(v^{\prime}=1\right)$ and $A^{2} \Sigma\left(v^{\prime}=0\right)$ were caused by vibrational energy transfer in an atmospheric pressure gas. An interference filter showing transmission at $307 \pm 15 \mathrm{~nm}$ was placed in front of the ICCD camera to eliminate the stray laser light. The radial distribution of the $\mathrm{OH}$ density was obtained from the distribution of the LIF intensity along the path of the laser beam. The axial distribution of the $\mathrm{OH}$ density was obtained by changing the distance between the laser beam and the top of the quartz tube. In the measurement of the density of atomic oxygen, the wavelength of the OPO laser was tuned at $225.58 \mathrm{~nm}$, by which atomic oxygen in the ground state $\left(2 p^{43} P\right)$ is excited to the $3 p^{3} P$ state by absorbing two photons of the laser beam. The excited $3 p^{3} P$ state emitted fluorescence at $844.64 \mathrm{~nm}$ owing to the spontaneous transition to the $3 s^{3} S$ state. The laser beam was injected into the effluent in the same manner as that in the Rayleigh scattering experiment, and fluorescence was captured using the same ICCD camera via an interference filter at the fluorescence wavelength. The intensity of the laser beam was weakened sufficiently to eliminate the production of atomic oxygen from molecular oxygen by the flash photolysis of the OPO laser beam.

\section{Results}

The ignition probability of the premixed burner flame is shown in Table I as a function of the energy of the Nd:YAG laser pulse. The ignition probability was defined as the ratio of the successful ignition in twenty repetitive experiments under the same experimental conditions. When DBD was switched off and water vapor was not added to the premixed gas, we observed an increase in ignition probability with the energy of the Nd:YAG laser pulse. The laser 
energy was varied by changing the delay time between the triggers to the flash lamp and the Pockels cell for Q-switching while keeping the discharge energy of the flash lamp. The ignition probability was low $(\leq 5 \%)$ at laser energies below $1.7 \mathrm{~mJ} /$ pulse, but it was improved up to $35 \%$ by switching on DBD. When water vapor was added to the premixed gas, we did not achieve ignition even at a high laser energy of $2.65 \mathrm{~mJ} /$ pulse. However, an ignition probability of $100 \%$ was realized in the effluent of DBD at a laser energy of $2.65 \mathrm{~mJ} / \mathrm{pulse}$, as shown in Table I, even when water vapor was added to the premixed gas.

Figure 2 shows shadowgraph images of the flame kernels that were observed at various delay times after the irradiation of the Nd:YAG laser pulse. These images were extracted from a high-speed movie. We did not produce DBD or add water vapor in this experiment. The energy of the Nd:YAG laser was $2.3 \mathrm{~mJ} /$ pulse. As shown in Figs. 2(a)-2(d), the outward propagation of the flame kernel was initiated from the focal point of the Nd:YAG laser beam. When the bottom part of the flame kernel arrived at the top of the quartz tube or the nozzle of the laboratory-made burner, it was blown up by the premixed gas provided from the nozzle, as shown in Fig. 2(e). The quasi-steady-state flame shown in Fig. 2(f) was realized $10 \mathrm{~ms}$ after the irradiation of the Nd:YAG laser pulse.

We roughly approximated the shape of the propagating flame kernel using an ellipsoid and evaluated the effective radius of the flame kernel. The effective radius was defined as $r=a^{1 / 3} b^{2 / 3}$, where $a$ and $b$ are the short and long radii of the approximated ellipsoid, respectively. The temporal evolution of the effective radius of the flame kernel is plotted in Fig. 3. The energy of the Nd:YAG laser was $2.3 \mathrm{~mJ} /$ pulse. The slope of the curve shown in Fig. 3 represents the average propagation speed of the flame kernel. A high propagation speed was observed immediately after the irradiation of the Nd:YAG laser pulse, which may be a result of the high rates of combustion reactions due to the high gas temperature of the laser-induced plasma. Subsequently, the propagation speed decreased, and we observed a constant propagation speed $\sim 200 \mu$ s after the irradiation of the Nd:YAG laser pulse. The constant propagation speed of the flame kernel without DBD and water vapor was $2.6 \mathrm{~m} / \mathrm{s}$; however, an increased propagation speed of $3.1 \mathrm{~m} / \mathrm{s}$ was observed by producing DBD. The amplitude of the high voltage for producing DBD was $5 \mathrm{kV}$ in this experiment. The increase in propagation speed by the production of DBD was also observed in the premixed gas with water vapor. The propagation speed without DBD was $2.2 \mathrm{~m} / \mathrm{s}$ in the premixed gas with water vapor; it was improved to $2.4 \mathrm{~m} / \mathrm{s}$ by the production of DBD at a voltage of $5 \mathrm{kV}$.

The shape of the flame kernel observed in the presence of DBD was roughly similar to that shown in Fig. 2, when the amplitude of the high voltage was $5 \mathrm{kV}$. However, when we 
produced DBD at higher voltages, the shape of the flame kernel was distorted considerably in its bottom part, as shown in Fig. 4, where the amplitudes of the high voltage were 10 and 14 $\mathrm{kV}$. In addition, it is understood from Fig. 4 that the bottom part of the flame kernel arrived at the burner nozzle at an earlier delay time at a higher discharge voltage; however, the position of the top part of the flame kernel was roughly independent of the discharge voltage. This means that the propagation speed of the flame kernel was increased in the region with a short distance from the nozzle.

Figure 5 shows the radial distribution of the gas temperature in the effluent of DBD. The distance from the top of the quartz tube was $3 \mathrm{~mm}$, and the discharge voltage was $10 \mathrm{kV}$. As shown in the figure, the increase in gas temperature caused by the production of DBD was insignificant at only $5 \mathrm{~K}$. The discharge power, which was evaluated using the V-Q Lissajous method, was approximately $0.5 \mathrm{~W}$ under the experimental conditions used.

The radial distribution of the $\mathrm{OH}$ density in the effluent of DBD is shown in Fig. 6(a). The discharge voltage was $10 \mathrm{kV}$. The $\mathrm{OH}$ density was examined at various distances from the top of the quartz tube, and the radial distributions at three distances are shown in Fig. 6(a). As has been reported in our previous paper, ${ }^{35)}$ we have to be careful about the spatial distributions of the rotational temperature and collisional quenching frequency in the measurement of the $\mathrm{OH}$ density by LIF spectroscopy. We judged that the spatial distribution of the rotational temperature was negligible since the gas temperature was not affected by DBD, as shown in Fig. 5. The frequency of collisional quenching was examined by measuring the temporal decay of the LIF intensity. As a result, we observed that the collisional quenching frequency was independent of the position under the experimental conditions used. Therefore, it was confirmed that the distribution of the LIF intensity represented the distribution of the relative $\mathrm{OH}$ radical density. Figure 6(b) shows the axial distribution of the $\mathrm{OH}$ density. The $\mathrm{OH}$ densities shown in Fig. 6(b) are averages of the radial distributions shown in Fig. 6(a). As shown in Fig. 6(b), the axial decay of the $\mathrm{OH}$ density was gentle, and the $\mathrm{OH}$ density at a distance of $20 \mathrm{~mm}$ from the top of the quartz tube was roughly half of that in the vicinity of the quartz tube. In addition, we estimated the density of $\mathrm{H}_{2} \mathrm{O}$, which was added by water bubbling, to be $3.5 \times 10^{17} \mathrm{~cm}^{-3}$ by comparing the collisional quenching frequencies of laser-excited $\mathrm{OH}\left(A^{2} \Sigma\right)$ $\left(0.75 \times 10^{9}\right.$ and $1.0 \times 10^{9} \mathrm{~s}^{-1}$ without and with water bubbling, respectively).

The radial distribution and axial decay of the density of atomic oxygen are shown in Fig. 7. The discharge voltage was $10 \mathrm{kV}$. The densities of atomic oxygen shown in Fig. 7(b) are averages of the radial distributions shown in Fig. 7(a). Since it was necessary to use a reduced energy for the OPO laser pulse to eliminate atomic oxygen produced by flash 
photolysis, we detected low LIF intensities, which may be one reason for the data scattering in the axial decay shown in Fig. 7(b). However, it can be said that the axial decay of the density of atomic oxygen was steeper than that of the $\mathrm{OH}$ radical density.

\section{Discussion}

The effect of DBD on the ignition property of the premixed burner flame is clearly shown in Table I. It is well known that a steady-state premixed burner flame is realized when the $\sin \theta$ component of the gas flow velocity is balanced with the burning velocity or propagation speed of the flame kernel, where $\theta$ represents the angle between the conical flame kernel and the flow axis. ${ }^{36)}$ In the ignition process, the propagation speed of the flame kernel competes with the flow velocity of the premixed gas. If the propagation speed of the flame kernel is higher than the flow velocity, which is $2 \mathrm{~m} / \mathrm{s}$ at its maximum under the present experimental conditions, the bottom part of the flame kernel can reach the top of the quartz tube or the nozzle of the burner; in this case, we observe the successful ignition of the premixed burner flame. An example of the successful ignition is shown in Fig. 2. On the other hand, if the propagation speed of the flame kernel is insufficient, the flame kernel cannot reach the burner nozzle. In this case, the flame kernel was blown off by the premixed gas in the upper direction, resulting in the failure of ignition. Therefore, it is reasonable that the improvement of the ignition probability is linked to the increased propagation speed of the flame kernel shown in Fig. 3. The decreases in the ignition probability and propagation speed of the flame kernel in the presence of water vapor are considered to be due to the fact that water vapor works as a heat sink in a reaction field.

The propagation speed of the flame kernel is determined by the rate of combustion reaction. Hence, the increase in the propagation speed of the flame kernel (Fig. 3) indicates the increase in the rate of combustion reaction by the production of DBD. Since the increase in gas temperature by the production of DBD is negligible as shown in Fig. 5, thermal effects do not contribute to the increase in reaction rate. In other words, the increase in reaction rate or that in the propagation speed of the flame kernel is caused by nonequilibrium effects. In addition, the laminar gas flow is maintained in the observation region and no change in flow field is observed even in the presence of DBD. Therefore, it is considered that the sources of the nonequilibrium effects are reactive radicals produced in DBD.

The comparison between the propagation of the flame kernel shown in Fig. 4 and the measurements of radical densities shown in Figs. 6 and 7 gives us an important understanding of the effective reactive species for increasing the rate of combustion reaction. Figure 4 indicates 
that the increase in the propagation speed of the flame kernel with the help of DBD is marked in its bottom part; the propagation speed of the top part of the flame kernel is not affected by DBD. This result strongly suggests that the reactive species that can enhance combustion reactions has a high density in the region close to the nozzle of the burner. The distorted shape of the flame kernel in the bottom part also suggests more significant effects of DBD-produced reactive species in the region close to the nozzle. On the other hand, as shown in Fig. 6(b), the $\mathrm{OH}$ radical density in the top part of the flame kernel $(z \sim 20 \mathrm{~mm})$ is higher than half of that in the vicinity of the nozzle, whereas the density of atomic oxygen at $z \sim 20 \mathrm{~mm}$ from the nozzle is approximately one order of magnitude lower than that in the vicinity of the nozzle. Therefore, the axial distribution of the density of atomic oxygen has a higher correlation with the spatial variation in the propagation speed of the flame kernel.

As described above, the present experimental results suggest that atomic oxygen works more effectively than $\mathrm{OH}$ radicals for the improvement of the ignition property of the premixed burner flame. The importance of atomic oxygen has been pointed out in the literature $;^{4,5,26-28)}$ in addition, our previous work has concluded that the increase in burning velocity in a steady-state premixed burner flame is due to the production of atomic oxygen in the preheating zone by the superposition of DBD. ${ }^{33)}$ The contributions of metastable states of atomic oxygen $\left[\mathrm{O}\left({ }^{1} D\right)\right]$ and $\mathrm{Ar}$ are another possible reason, but the densities of the metastable states in the effluent of DBD are expected to be negligible considering the rate coefficients of collisional quenching. ${ }^{37,38)}$ On the other hand, note here that the present experimental results do not give us knowledge of the reactivities of an atomic oxygen and a $\mathrm{OH}$ radical. We have evaluated that the absolute density of $\mathrm{OH}$ radicals is lower than $1 \times 10^{13} \mathrm{~cm}^{-3}$. This absolute density was evaluated from the decay time constant ( $25 \mathrm{~ms}$ ) of the $\mathrm{OH}$ density in the afterglow phase of the burst-mode DBD and the rate coefficient $\left(4.6 \times 10^{-12} \mathrm{~cm}^{3} / \mathrm{s}\right)$ for the self-association reaction of two $\mathrm{OH}$ radicals to form $\mathrm{H}_{2} \mathrm{O}_{2} \cdot{ }^{39)}$ On the other hand, the absolute density of atomic oxygen was estimated to be on the order of $10^{15} \mathrm{~cm}^{-3}$. This density was estimated by comparing the LIF intensity observed in the effluent of DBD with that observed in the steady-state flame. The density of atomic oxygen in the steady-state flame was roughly evaluated by zero-dimensional calculation using CHEMKIN. Accordingly, the absolute density of atomic oxygen is estimated to be much higher than that of $\mathrm{OH}$ radicals, and the much higher density may be one reason for the experimental results showing the importance of atomic oxygen for the improved ignition property of a premixed burner flame. 


\section{Conclusions}

In this work, we examined the correlation between the propagation speed of the flame kernel and the densities of reactive species in the effluent of DBD. The experimental results clearly show that the density of atomic oxygen has a higher correlation with the propagation speed of the flame kernel than that of $\mathrm{OH}$ radicals, indicating that atomic oxygen is the key radical for the improvement of the ignition property of a premixed burner flame. One reason for the effectiveness of atomic oxygen is its higher density than $\mathrm{OH}$. The present experimental results do not give a comparison between the reactivities of an atomic oxygen and a $\mathrm{OH}$ radical, but it is considered that the higher density of atomic oxygen than of $\mathrm{OH}$ is realized in most cases of plasma-assisted ignition.

\section{Acknowledgment}

This work was supported by JSPS KAKENHI Grant Number 25286078. 


\section{References}

1) S. M. Starikovskaia, J. Phys. D 39, R265 (2006).

2) A. Starikovskiy and N. Aleksandrov, Prog. Energy Combust. Sci. 39, 61 (2013).

3) Y. Ju and W. Sun, Prog. Energy Combust. Sci. 48, 21 (2015).

4) Y. Ju, J. K. Lefkowitz, C. B. Reuter, S. H. Won, X. Yang, S. Yang, W. Sun, Z. Jiang, and Q. Chen, Plasma Chem. Plasma Process. 36, 85 (2016).

5) N. A. Popov, Plasma Sources Sci. Technol. 25, 043002 (2016).

6) S. B. Leonov, D. A. Yarantsev, A. P. Napartovich, and I. V. Kochetov, IEEE Trans. Plasma Sci. 34, 2514 (2006).

7) I. Esakov, L. P. Grachev, K. V. Khodataev, V. A. Vinogradov, and D. M. van Wie, IEEE Trans. Plasma Sci. 34, 2497 (2006).

8) S. V. Leonov and D. A. Yarantsev, Plasma Sources Sci. Technol. 16, 132 (2007).

9) T. Ombrello, X. Qin, and Y. Ju, AIAA J. 44, 142 (2006).

10) T. Ombrello, Y. Ju, and A. Fridman, AIAA J. 46, 2424 (2008).

11) G. Pilla, D. Galley, D. A. Kacoste, F. Lacas, D. Veynante, and C. O. Laux, IEEE Trans. Plasma Sci. 34, 2471 (2006).

12) X. Rao, S. Hammack, T. Lee, C. Carter, and I. B. Matveev, IEEE Trans. Plasma Sci. 38, 3265 (2010).

13) Q. L. L. Pham, D. A. Lacoste, and C. O. Laux, IEEE Trans. Plasma Sci. 39, 2264 (2011).

14) S. Stange, Y. Kim, V. Ferreri, L. A. Rosocha, and D. M. Coates, IEEE Trans. Plasma Sci. 33, 316 (2005).

15) K. Shinohara, N. Takada, and K. Sasaki, J. Phys. D 42, 182008 (2009).

16) E. S. Stockman, S. H. Zaidi, R. B. Miles, C. D. Carter, and M. D. Ryan, Combust. Flame 156, 1453 (2009).

17) T. Ombrello, S. H. Won, Y. Ju, and S. Williams, Combust. Flame 157, 1906 (2010).

18) T. Ombrello, S. H. Won, Y. Ju, and S. Williams, Combust. Flame 157, 1916 (2010).

19) S. Y. Pancheshnyi, D. A. Lacoste, A. Bourdon, and C. O. Laux, IEEE Trans. Plasma Sci. 34, 2478 (2006).

20) N. L. Aleksandrov, S. V. Kindysheva, I. N. Kosarev, S. M. Starikovskaia, and A. Y. Starikovskii, Proc. Combust. Inst. 32, 205 (2009).

21) G. Lou, A. Bao, M. Nishihara, S. Keshav, Y. G. Utkin, J. W. Rich, W. R. Lempert, and I. V. Adamovich, Proc. Combust. Inst. 31, 3327 (2007). 
22) A. Bao, Y. G. Utkin, S. Keshav, G. Lou, and I. V. Adamovich, IEEE Trans. Plasma Sci. 35, 1628 (2007).

23) W. Sun, M. Uddi, T. Ombrello, S. H. Won, C. Carter, and Y. Ju, Proc. Combust. Inst. 33, 3211 (2011).

24) W. Sun, S. H. Won, T. Ombrello, C. Carter, and Y. Ju, Proc. Combust. Inst. 34, 847 (2013).

25) L. Wu, J. Lane, N. P. Cernansky, D. L. Miller, A. Fridman, and A. Y. Starikovskiy, Proc. Combust. Inst. 33, 3219 (2011).

26) W. Kim, M. G. Mungal, and M. A. Cappelli, Combust. Flame 157, 374 (2010).

27) I. N. Kosarev, N. L. Aleksandrov, S. V. Kindysheva, S. M. Starikovskaia, and A. Y. Starikovskii, Combust. Flame 156, 221 (2009).

28) W. Sun, M. Uddi, T. Ombrello, S. H. Won, C. Carter, and Y. Ju, Proc. Combust. Inst. 33, 3211 (2011).

29) W. Wu, C. A. Fuh, and C. Wang, IEEE Trans. Plasma Sci. 43, 3986 (2015).

30) C. A. Fuh, W. Wu, and C. Wang, Eur. Phys. J. D 71, 302 (2017).

31) K. Zaima and K. Sasaki, Jpn. J. Appl. Phys. 53, 066202 (2014).

32) K. Zaima and K. Sasaki, Jpn. J. Appl. Phys. 53, 110309 (2014).

33) K. Zaima, H. Akashi, and K. Sasaki, Jpn. J. Appl. Phys. 55, 016201 (2016).

34) K. Zaima and K. Sasaki, Jpn. J. Appl. Phys. 55, 086201 (2016).

35) H. Ishigame, S. Nishiyama, and K. Sasaki, Jpn. J. Appl. Phys. 54, 01AF02 (2015).

36) A. G. Gaydon and H. G. Wolfhard, Flames: Their Structure, Radiation and Temperature (Chapman and Hall, London, 1979) 4th ed., p. 58.

37) S. R. Kinnersly and J. N. Murrell, J. Chem. Soc., Faraday Trans. 2 74, 600 (1978).

38) K. Sasaki and R. Asaoka, Jpn. J. Appl. Phys. 50, 08JB02 (2011).

39) F. Tochikubo, S. Uchida, and T. Watanabe, Jpn. J. Appl. Phys. 43, 315 (2004). 
Table I. Ignition probabilities of premixed burner flame under various experimental conditions.

\begin{tabular}{ccccc}
\hline \hline $\begin{array}{c}\text { Laser energy } \\
(\mathrm{mJ} / \text { pulse })\end{array}$ & $\begin{array}{c}\text { without DBD } \\
\text { without } \mathrm{H}_{2} \mathrm{O}\end{array}$ & $\begin{array}{c}\text { with DBD } \\
\text { without } \mathrm{H}_{2} \mathrm{O}\end{array}$ & $\begin{array}{c}\text { without DBD } \\
\text { with } \mathrm{H}_{2} \mathrm{O}\end{array}$ & $\begin{array}{c}\text { with DBD } \\
\text { with } \mathrm{H}_{2} \mathrm{O}\end{array}$ \\
\hline 1.2 & $0 \%$ & $0 \%$ & $0 \%$ & $0 \%$ \\
1.45 & $0 \%$ & $5 \%$ & $0 \%$ & $0 \%$ \\
1.7 & $5 \%$ & $35 \%$ & $0 \%$ & $0 \%$ \\
2.0 & $75 \%$ & $80 \%$ & $0 \%$ & $20 \%$ \\
2.3 & $90 \%$ & $85 \%$ & $0 \%$ & $80 \%$ \\
2.65 & $100 \%$ & $100 \%$ & $0 \%$ & $100 \%$ \\
\hline \hline
\end{tabular}




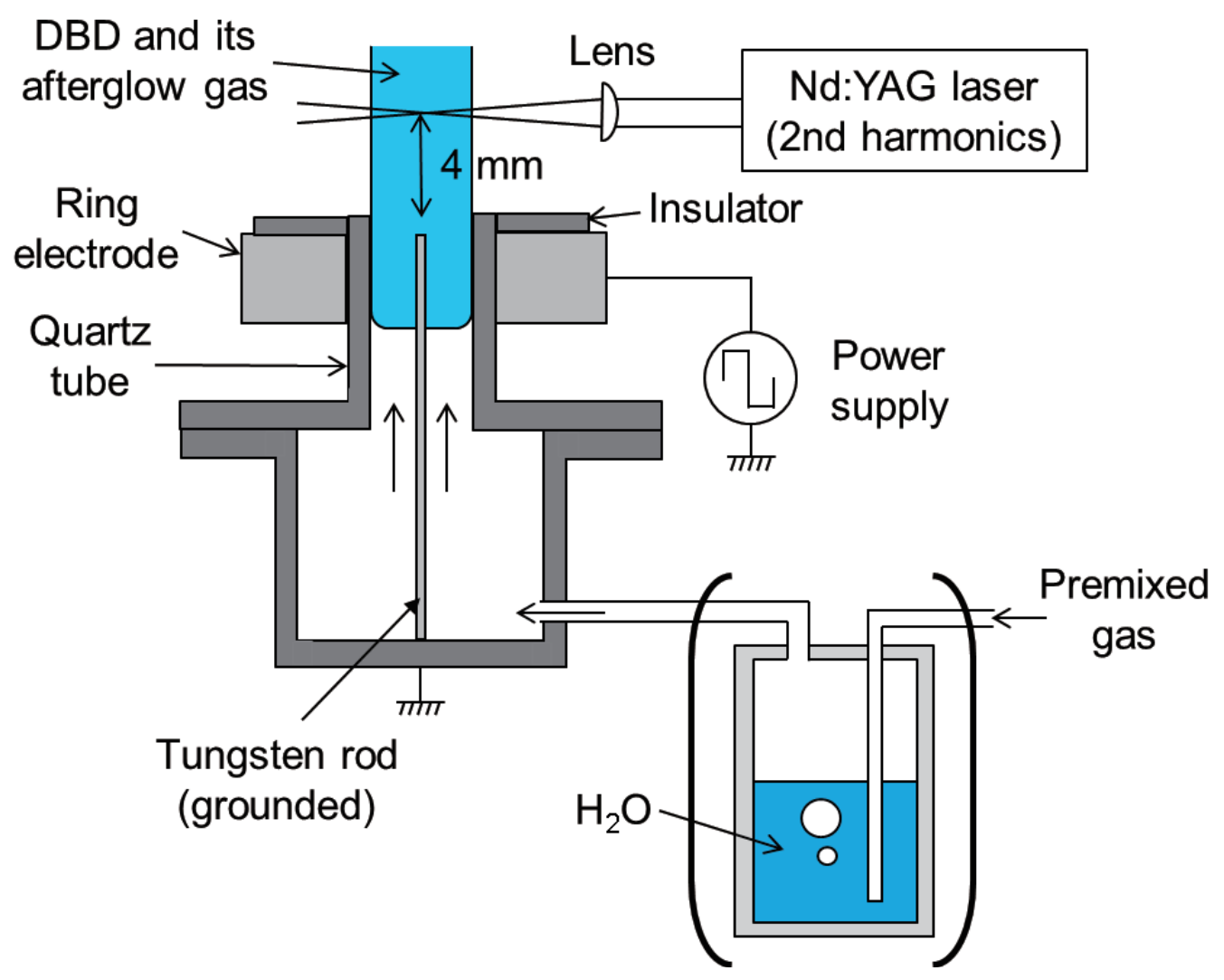

Fig. 1. Schematic diagram of the experimental apparatus. 


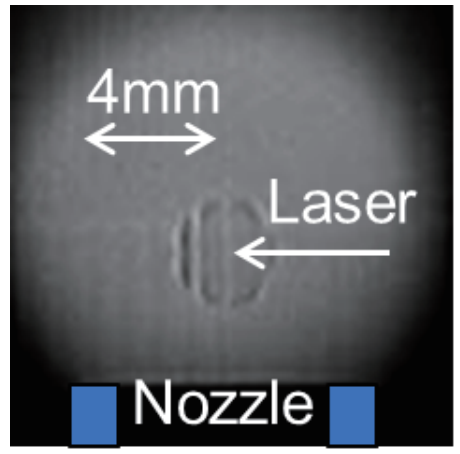

(a)

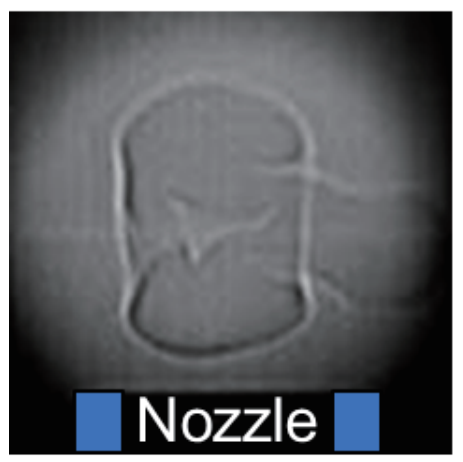

(c)

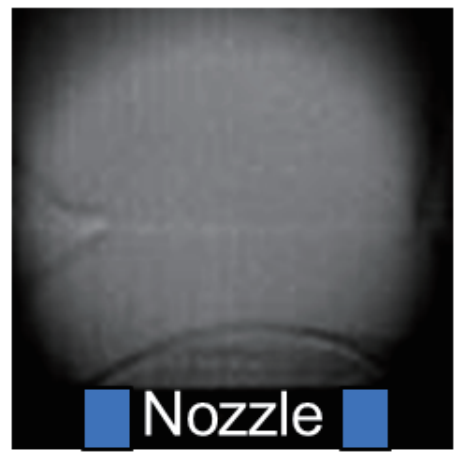

(e)

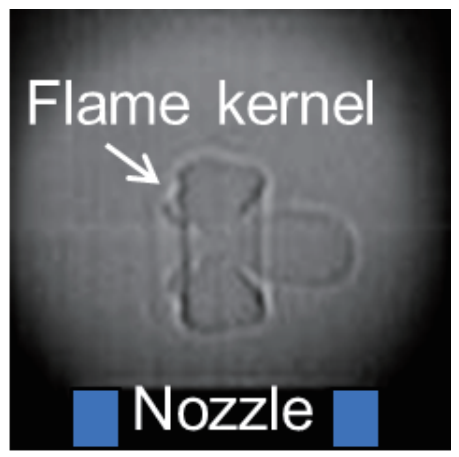

(b)

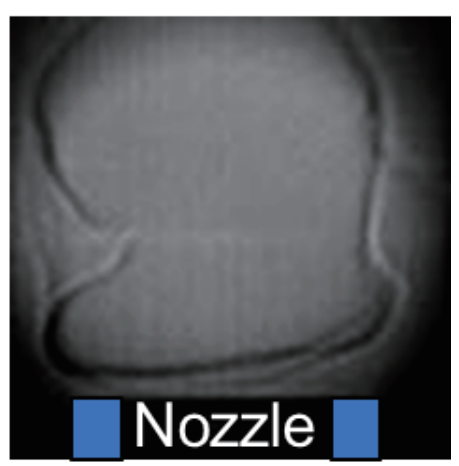

(d)

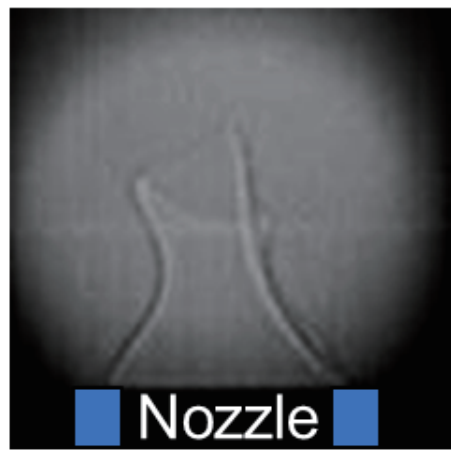

(f)

Fig. 2. Shadowgraph images of flame kernels observed at various delay times after the irradiation of the Nd:YAG laser pulse: (a) $0.02 \mathrm{~ms}$, (b) $0.14 \mathrm{~ms}$, (c) $0.51 \mathrm{~ms}$, (d) $1.33 \mathrm{~ms}$, (e) $2.35 \mathrm{~ms}$, and (f) $10.0 \mathrm{~ms}$. DBD was switched off and the laser energy was $2.3 \mathrm{~mJ} /$ pulse. 


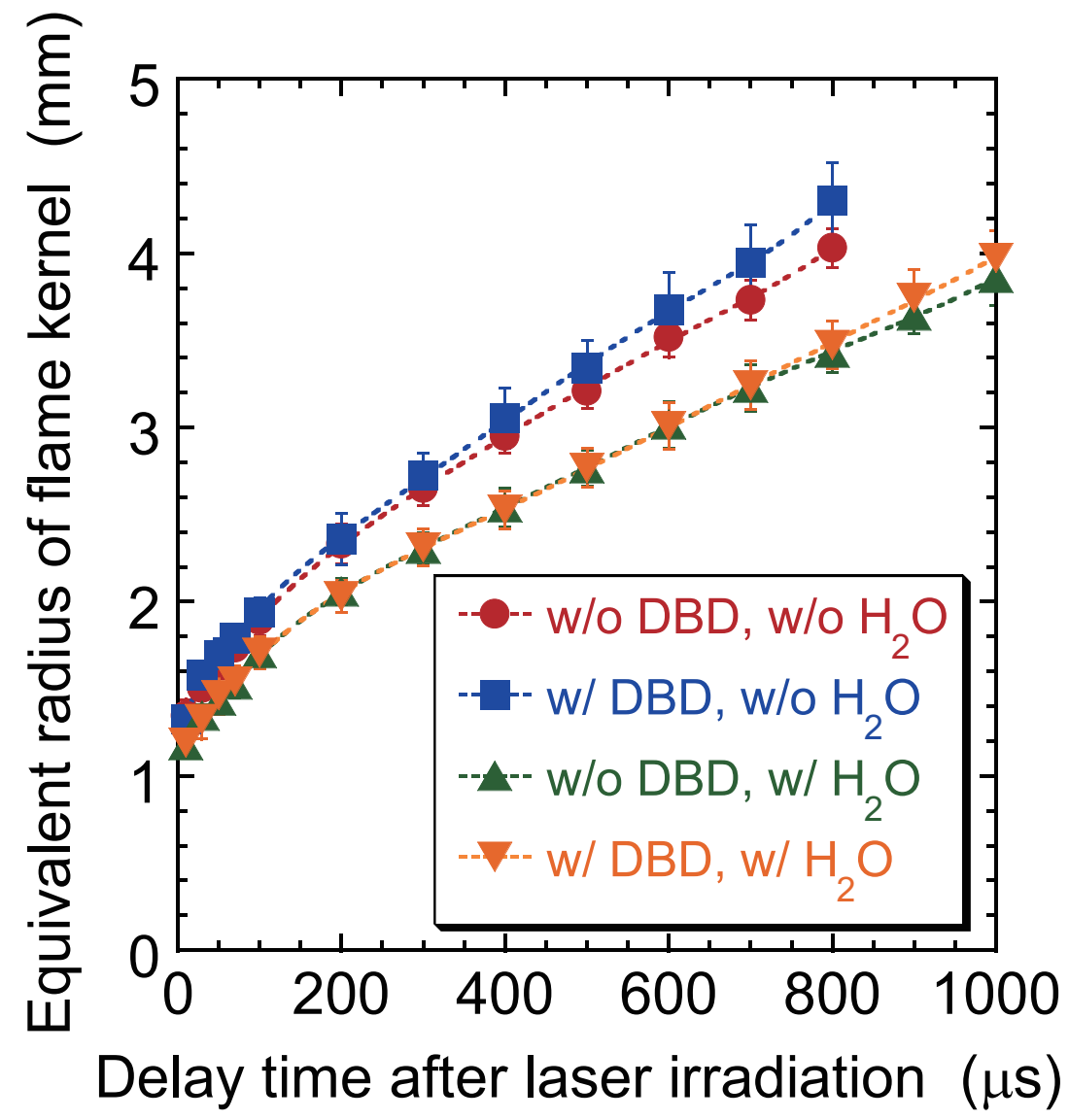

Fig. 3. Equivalent radius of the flame kernel as a function of the delay time after the irradiation of the Nd:YAG laser pulse. 


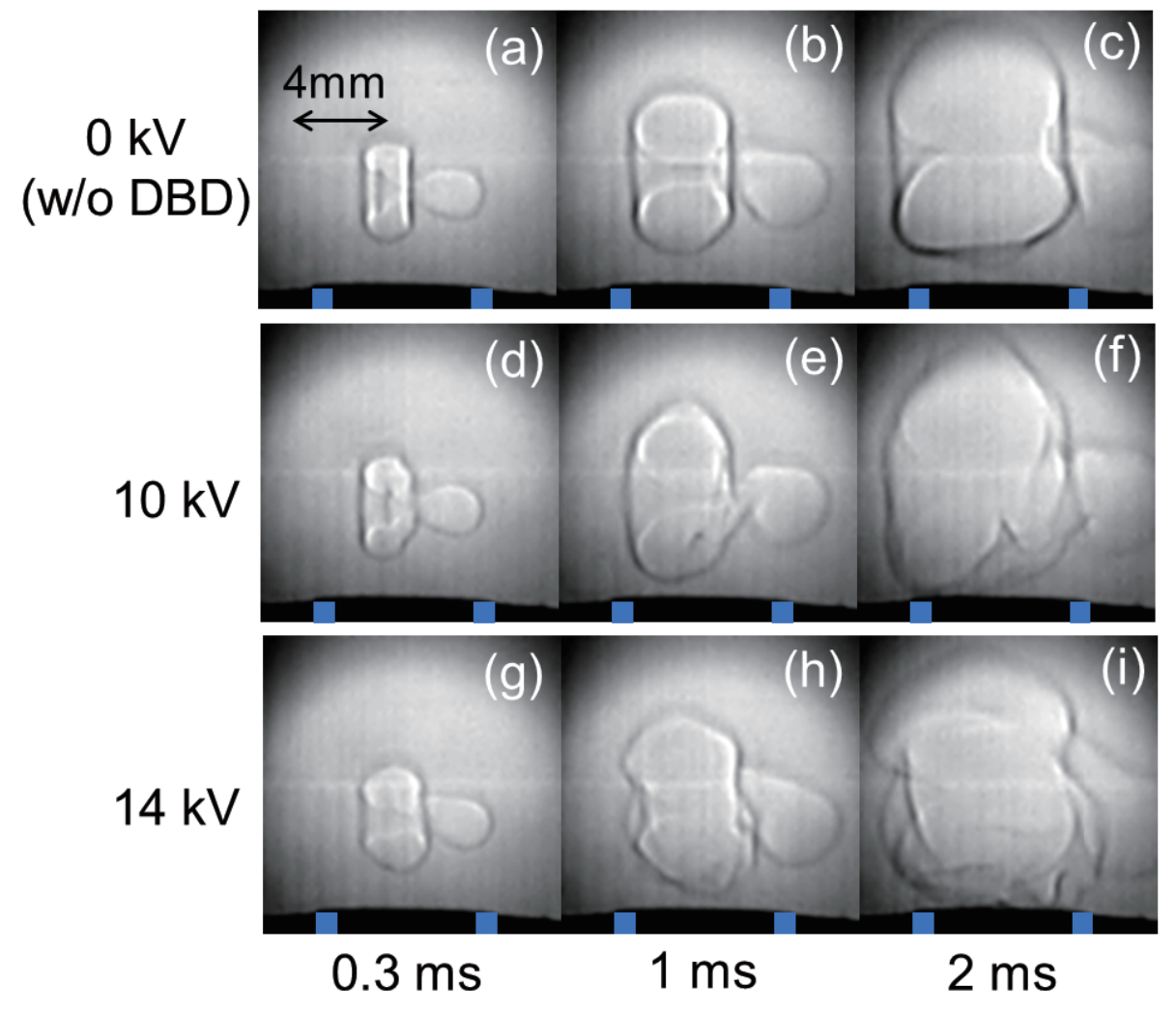

Fig. 4. Shadowgraph images of flame kernels observed (a)-(c) without DBD, (d)-(f) in the effluent of DBD produced at a discharge voltage of $10 \mathrm{kV}$, and (g)-(i) in the effluent of DBD produced at a discharge voltage of $14 \mathrm{kV}$. 


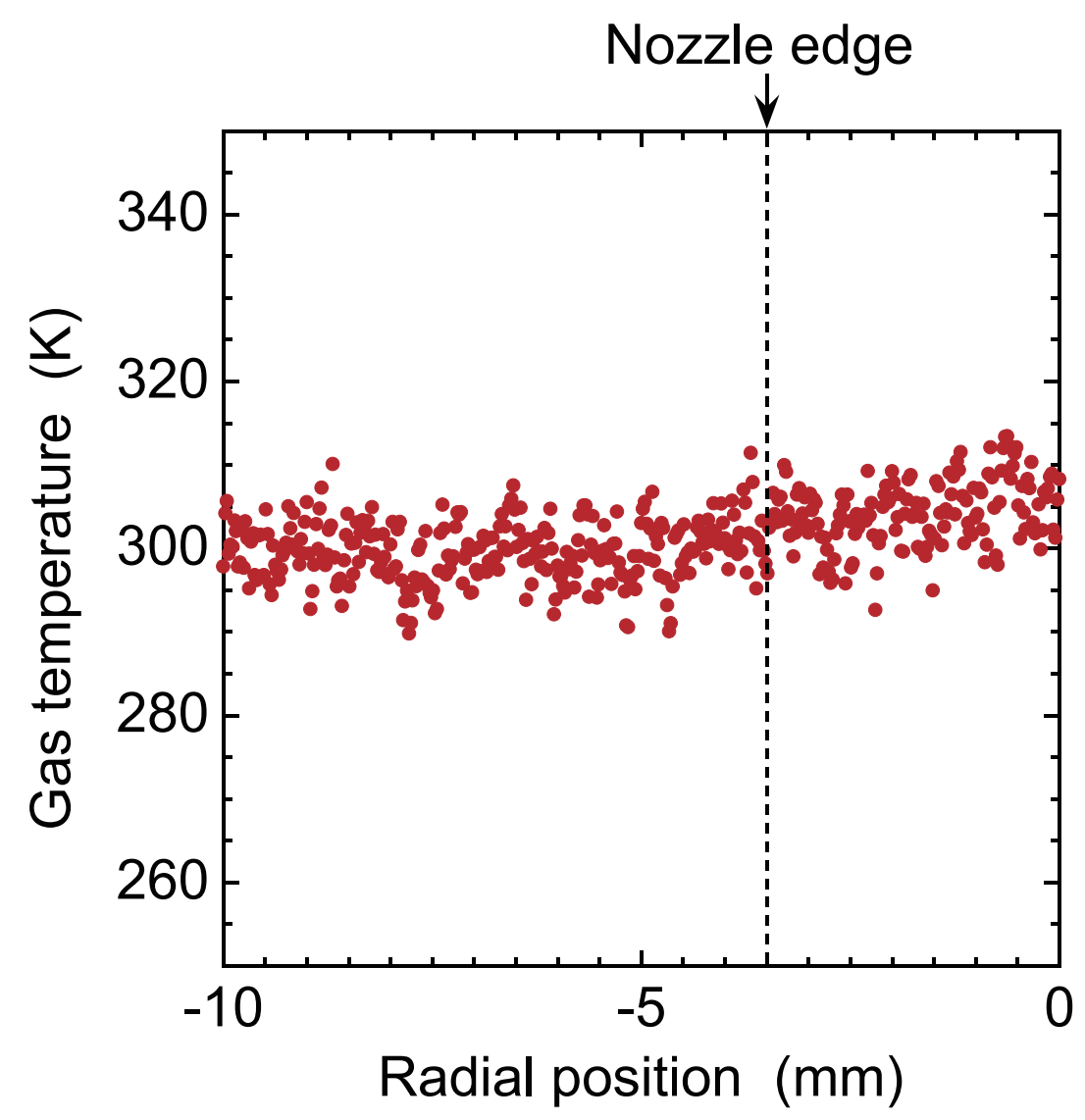

Fig. 5. Radial distribution of the gas temperature in the effluent of DBD. 

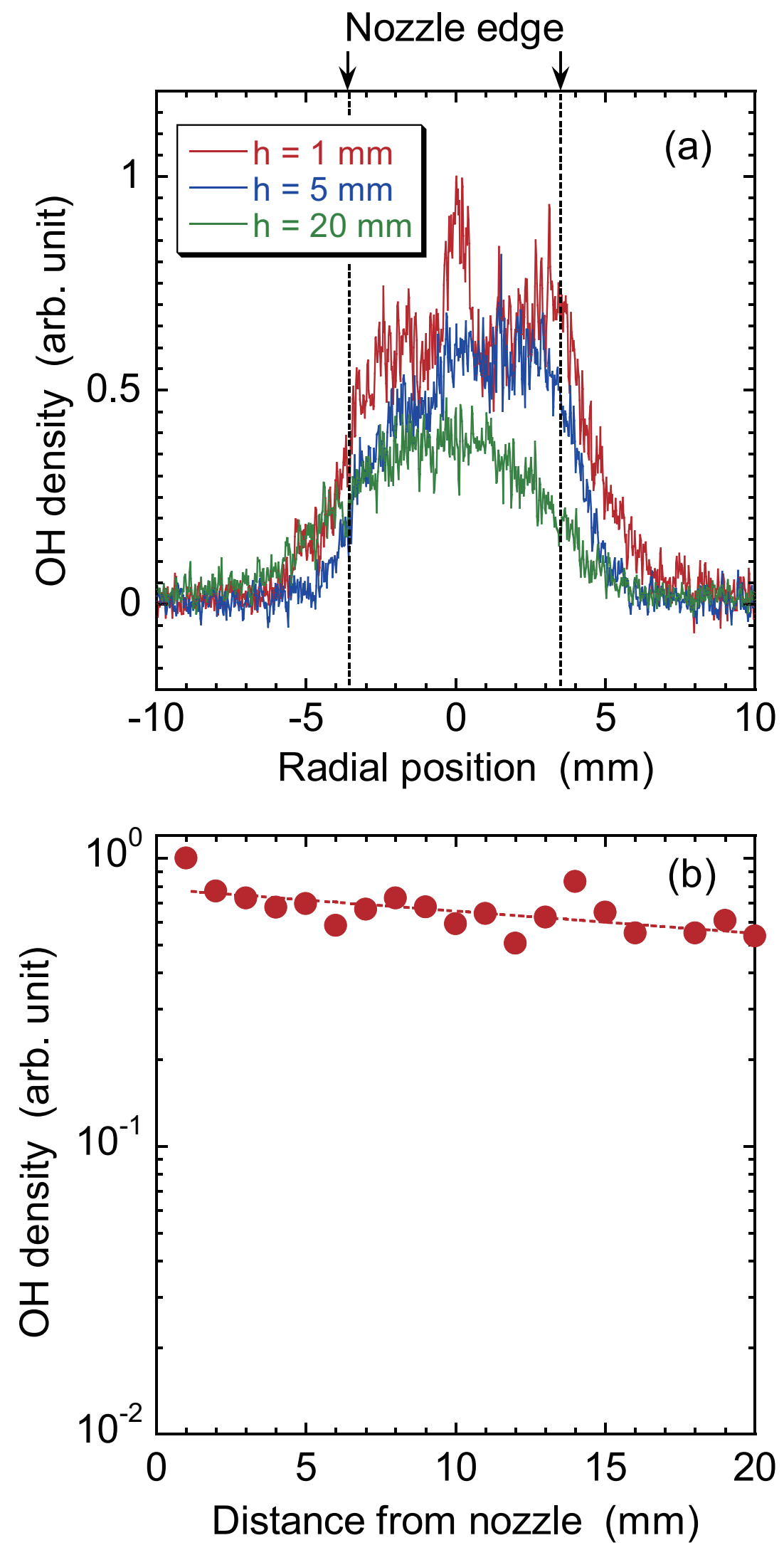

Fig. 6. (a) Radial distributions of the $\mathrm{OH}$ radical density at three axial distances from the nozzle. (b) Axial distribution of the radially averaged $\mathrm{OH}$ radical density. 

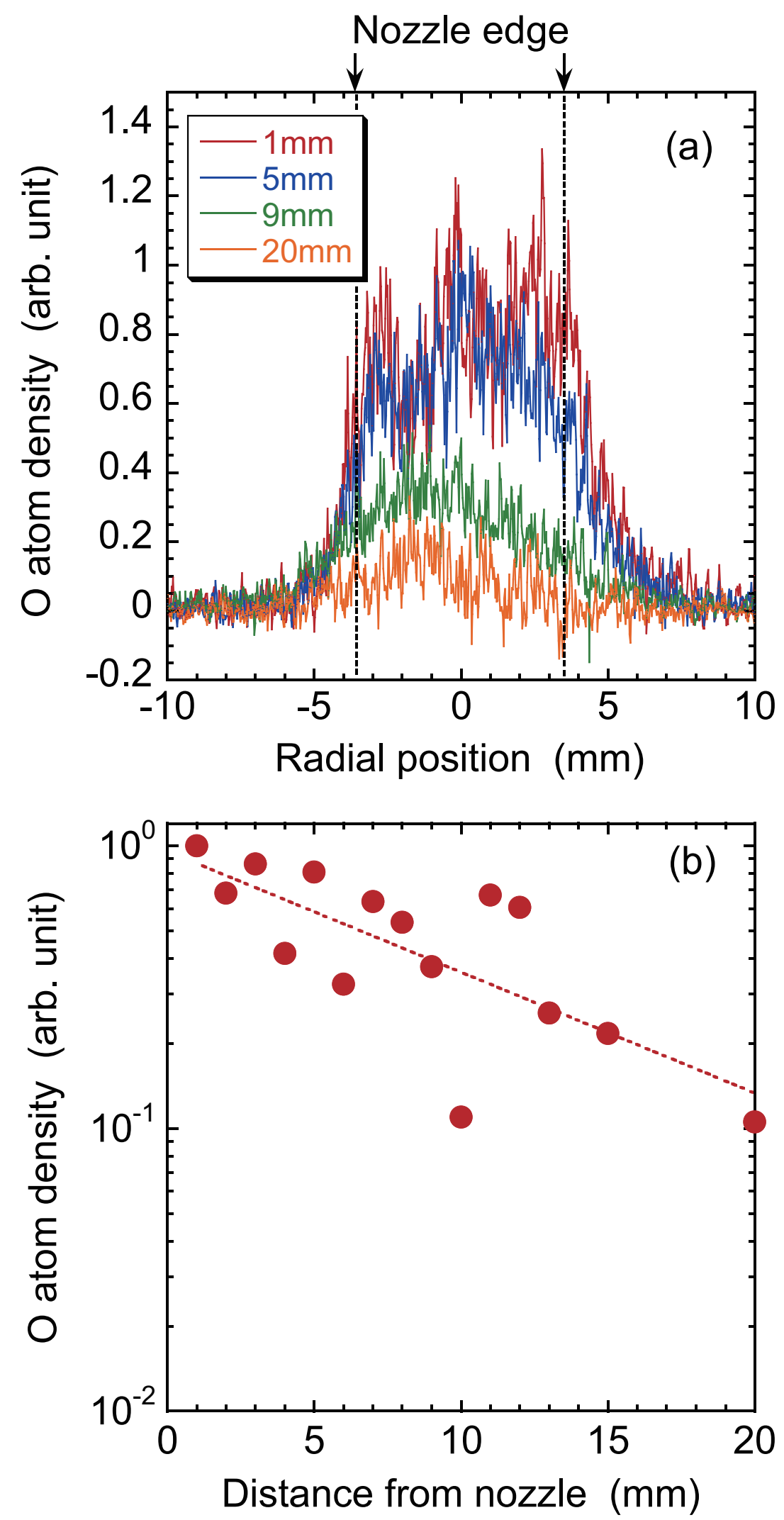

Fig. 7. (a) Radial distributions of the density of atomic oxygen at four axial distances from the nozzle. (b) Axial distribution of the radially averaged density of atomic oxygen. 